
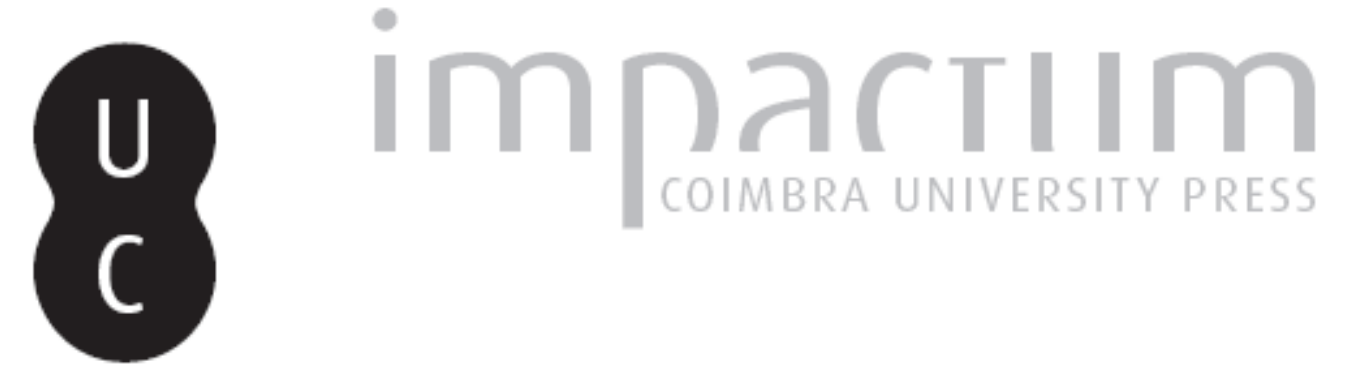

\title{
A proveniência do mármore dos capitéis do Templo Romano de Évora
}

Autor(es): $\quad$ Cabral, João M. Peixoto; Mustra, Carla O.; Hauschild, Theodor

Publicado por: Faculdade de Letras da Universidade de Coimbra

URL persistente:

URI:http://hdl.handle.net/10316.2/37705

DOI:

DOI:http://dx.doi.org/10.14195/1647-8657_43_7

Accessed : $\quad$ 26-Apr-2023 13:39:25

A navegação consulta e descarregamento dos títulos inseridos nas Bibliotecas Digitais UC Digitalis, UC Pombalina e UC Impactum, pressupõem a aceitação plena e sem reservas dos Termos e Condições de Uso destas Bibliotecas Digitais, disponíveis em https://digitalis.uc.pt/pt-pt/termos.

Conforme exposto nos referidos Termos e Condições de Uso, o descarregamento de títulos de acesso restrito requer uma licença válida de autorização devendo o utilizador aceder ao(s) documento(s) a partir de um endereço de IP da instituição detentora da supramencionada licença.

Ao utilizador é apenas permitido o descarregamento para uso pessoal, pelo que o emprego do(s) título(s) descarregado(s) para outro fim, designadamente comercial, carece de autorização do respetivo autor ou editor da obra.

Na medida em que todas as obras da UC Digitalis se encontram protegidas pelo Código do Direito de Autor e Direitos Conexos e demais legislação aplicável, toda a cópia, parcial ou total, deste documento, nos casos em que é legalmente admitida, deverá conter ou fazer-se acompanhar por este aviso.

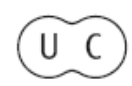


CONIMBRIGA

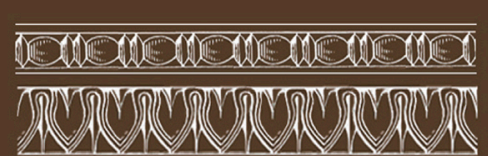

INSTITUTO DE ARQUEOLOGIA

VOLUME XLIII - 2004

FACULDADE DE LETRA

UNIVERSIDADE DE COIMBRA 
JoÃo M. Peixoto CABRAL

Instituto Tecnológico e Nuclear (Lisboa)

CARLa O. Mustra

Instituto Tecnológico e Nuclear (Lisboa)

THEODOR HAUSCHILD

Instituto Arqueológico Alemão

\section{A PROVENIÊNCIA DO MÁRMORE DOS CAPITÉIS DO TEMPLO ROMANO DE ÉVORA \\ "Conimbriga" XLIII (2004) p. 171-177}

RESUMO: Análises isotópicas do mármore de dois fragmentos achados nas escavações arqueológicas realizadas junto do Templo Romano de Évora, os quais segundo as suas formas e medidas fizeram parte dos capitéis das colunas desmoronadas, mostraram que ele teria sido muito provavelmente extraído de uma pedreira do Alto Alentejo.

ABSTRACT: Isotopic analyses carried out on two marble fragments found in archaeological excavations close to the Roman Temple of Évora, which according to their forms and dimensions pertained to the capitals of the collapsed columns, have shown that the marble used in those capitals was very likely extracted from a quarry in Alto Alentejo. 
(Página deixada propositadamente em branco) 


\section{A PROVENIÊNCIA DO MÁRMORE DOS CAPITÉIS DO TEMPLO ROMANO DE ÉVORA}

\section{Introdução}

Na história do estudo dos capitéis do Templo Romano de Évora pensou-se como certo que o material dos mesmos proviria das pedreiras marmóreas localizadas não muito longe de Évora, na região entre Vila Viçosa e Estremoz. $\mathrm{O}$ facto de nas escavações arqueológicas realizadas junto do templo terem aparecido alguns fragmentos de mármore, que segundo as suas formas e medidas fizeram parte dos capitéis das colunas desmoronadas, levou-nos a procurar comprovar ou infirmar tal hipótese mediante o emprego de métodos físico-químicos.

Estes capitéis, de grandes dimensões, suscitam três questões essenciais. Em primeiro lugar, a questão relativa à procedência do material um mármore branco que, para ser utilizado na estrutura do monumento nomeadamente no suporte do peso das arquitraves de granito, dos frisos e das cornijas, precisa de, por um lado, uma consistência especial e, por outro, uma fineza estrutural que permitam aparelhar pormenores das volutas e da decoração vegetal oferecendo ainda um aspecto harmonioso e agradável. Estas características são próprias unicamente de certos mármores. No que respeita ao Templo de Évora, acresce o facto de que o mármore foi escolhido só para os capitéis e para as bases, enquanto os fustes foram trabalhados em granito o qual oferece uma superfície granulosa que foi coberta, evidentemente, com uma camada de estuque pintada de branco de modo a obter-se uma imitação daquele material. Por se conhecerem casos de importação de mármore, como aconteceu com um capitel da época de Augusto em Cartagena cujo mármore foi importado da Grécia, e, por outro lado, existirem pedreiras marmóreas no Alentejo cujos materiais têm sido estudados mediante a análise isotópica, pareceu-nos razoável que os fragmentos re- 
colhidos nas escavações arqueológicas junto do templo fossem igualmente submetidos a esse tipo de análise. $\mathrm{O}$ presente artigo tem por fim apresentar os resultados obtidos e as conclusões que foi possível retirar a partir deles.

A segunda questão relaciona-se com a aplicação do mármore. Quando na época de Augusto se iniciou a "marmorização" dos edifícios públicos, este material era aplicado para cobrir todos os elementos estruturais. A utilização selectiva de mármore em algumas partes da obra, como aconteceu em Évora só para os capitéis e bases sendo os fustes feitos noutro material foi excepcional. É verdade que existem fustes de granito, mas monolíticos, polidos na superfície e sem caneluras. Suspeitou-se, no caso de Évora, de que os capitéis teriam sido incorporados posteriormente ou que se trataria de uma medida de economia. A primeira suspeita é inteiramente infundada. $\mathrm{O}$ emprego selectivo de mármore de qualidade superior talvez se possa explicar pela circunstância de, no início, as pedreiras em exploração na Lusitânia não disporem de mármore em quantidade suficiente para revestir totalmente o Templo de Évora. É possível que futuras análises dos diferentes mármores empregados em monumentos romanos, como por exemplo os de Mérida, e um estudo sistemático das pedreiras marmóreas supostamente romanas situadas na zona de Vila Viçosa/Estremoz venham permitir o esclarecimento deste assunto.

A terceira questão abrange a apreciação estilística dos capitéis e o estudo da sua cronologia, tendo sido já motivo de exames e publicações de um de nós (Hauschild, 1988) e também de Fernandes (1999). São capitéis de estilo coríntio normal com formas de decoração vegetal, em particular de folhas de acanto, e volutas que têm evidentemente por modelo capitéis da época de Augusto como, por exemplo, os do Templo de Mars Ultor no Fórum de Augusto em Roma. Uma característica própria dos capitéis de Évora encontra-se nas flores do ábaco, das quais algumas mostram rebentos de acanto e não pinhas como foi comummente aceite. Outra característica importante desses capitéis consiste no facto de eles se encontrarem talhados em dois blocos, unidos ao nível da parte superior dos caulículos, seguindo uma tradição republicana que em Roma se acata ainda na $1 .^{a}$ metade do séc. I d. C. Nos capitéis de Évora encontram-se indícios atribuíveis a uma época posterior a Augusto, parecendo-nos provável que a sua data aproximada seja anterior ao fim da 1. - metade do séc. I d. C. O escasso espólio arqueológico até agora recolhido não contradiz esta avaliação. 


\section{Material e método experimental}

Examinaram-se dois fragmentos de mármore dos capitéis do Templo Romano de Évora, designadamente os seguintes. Fragmento A (EVT-90-95), procedente da sondagem 4/5 (fig. 1), camada 1 debaixo do muro da época medieval. Esta camada não foi tocada pela escavação de Cunha Rivara em 1845. Muitos fragmentos pequenos de mármore branco indicam uma destruição sistemática já antes da época medieval. Fragmento B (EVT-90-110), procedente da ampliação ocidental da sondagem 4, ou seja, de um lugar que foi removido pelas construções do Palácio da Inquisição e das escavações de Cunha Rivara. Segundo a planta das sondagens (fig. 1), os mencionados fragmentos de mármore foram encontrados imediatamente junto da parte frontal do templo.

De cada fragmento extraiu-se uma pequena amostra com uma broca de carboneto de tungsténio, tendo o cuidado de previamente retirar a camada superficial na zona de amostragem e de usar uma velocidade de rotação suficientemente baixa para não aquecer demasiado os materiais recolhidos. As amostras levaram as seguintes designações: amostra 1, a que foi extraída do fragmento A; amostra 2, a que foi extraída do fragmento B.

Ambas as amostras foram analisadas por meio da espectrometria de massa de dois dos seus elementos constituintes principais carbono e oxigénio recorrendo ao processo usado num estudo anterior (Cabral et al. 1992).

\section{Resultados e discussão}

Os resultados obtidos foram os seguintes. Amostra 1: ${ }^{13} \mathrm{C}=1,99$ $\% o ;{ }^{18} \mathrm{O}=4,80 \%$. Amostra $2:{ }^{13} \mathrm{C}=1,64 \%$ \% ${ }^{18} \mathrm{O}=4,76 \%$.

A fig. 2 mostra as projecções destas duas amostras num diagrama de ${ }^{13} \mathrm{C}$ em função de ${ }^{18} \mathrm{O}$, no qual se apresentam também os campos característicos das composições isotópicas dos mármores do Anticlinal de Estremoz (Cabral et al. 2001) e de diversos mármores brancos de várias pedreiras situadas na Itália, Grécia e Turquia, que foram exploradas durante a Antiguidade Clássica (Moens et al. 1992).

Como se pode ver na fig. 2, os pontos representativos das amostras 1 e 2 situam-se dentro do campo EA relativo aos mármores do Anticlinal de Estremoz, o que permite inferir que o mármore dos fragmen- 
tos analisados pode ter vindo do Alto Alentejo. Contudo, dado que nos sítios onde se encontram esses dois pontos se verifica a sobreposição de vários campos, entre os quais o campo A (característico dos mármores de Afrodisíade), o campo D (característico dos mármores de Dokimeion) e o campo U (característico dos mármores de Usak), é legítimo inferir ainda que o mármore dos fragmentos analisados pode ter vindo também destas três últimas pedreiras.

É interessante notar que os referidos pontos se localizam muito longe do campo $\mathrm{C}$, característico dos mármores de Carrara, o que mostra claramente que o mármore dos fragmentos analisados não é com certeza proveniente de Carrara.

\section{Conclusões}

Assim, atendendo a que as pedreiras de Afrodisias, de Dokimeion e de Usak se situam incomparavelmente mais longe de Évora do que as do Alto Alentejo, parece razoável concluir com base nos presentes resultados que o mármore dos capitéis do Templo Romano de Évora teria sido muito provavelmente extraído duma pedreira do Alto Alentejo.

Poderá concluir-se, além disso, atendendo ainda à data estimada para estes capitéis, que as pedreiras marmóreas alentejanas estariam já a funcionar no $2 .^{\circ}$ quartel do séc. I d. C., sendo possível portanto que o artista que operou em Évora o marmorarius tivesse tomado parte na pesquisa e extracção do mármore com vista na realização de tal obra. Sabemos que nessa época tinham sido já decorados edifícios públicos com mármore como, por exemplo, o suposto foro provincial de Augusta Emerita (de la Barrera) e o Teatro Romano de Lisboa, onde a inscrição da renovação com este material data do ano 57 d. C.

\section{REFERÊNCIAS}

Cabral, J. M. P., Vieira, M. C. R., Carreira, P. M., Figueiredo, M. O., Pena, T. P. e Tavares, A. (1992). "Preliminary study on the isotopic and chemical characterization of marbles from Alto Alentejo (Portugal)". In M. Waelkens, N. Herz and L. Moens (eds.), Ancient Stones: Quarrying, Trade and Provenance. Acta Archaeologica Lovaniensia, Monographiae 4, Leuven University Press, 191-8.

Cabral, J. M. P., Maciel, M. J., Lopes, L., Lopes, J. M. C., Marques, A. P. V., Mustra, C. O., e Carreira, P. M. (2001). "Petrographic and isotopic characterization of 
marble from the Estremoz Anticline: its application in identifying the sources of Roman works of art", Journal of Iberian Archaeology 3 121-8. "Complementary Note", Journal of Iberian Archaeology 4208.

De la Barrera, J. L. (2000). La Decoración Arquitectónica de los Foros de Augusta Emerita, 173.

Fernandes, L. M. M. (1999). Capitéis Romanos da Lusitânia Ocidental, Vol. II (tese de mestrado), Lisboa, 227-33.

Hauschild, T. (1988). "Untersuchungen am römischen Tempel von Évora", Madrider Mitteilungen 29 208-220 (sobretudo, 214-215).

Moens, L., De Paepe, P. e Waelkens, M. (1992). "Multidisciplinary research and cooperation: keys to a successful provenance determination of white marbles". In M. Waelkens, N. Herz and L. Moens (eds.), Ancient Stones: Quarrying, Trade and Provenance. Acta Archaeologica Lovaniensia, Monographiae 4, Leuven University Press, 247-52.

\section{AGRADECIMENTO}

Este trabalho foi subsidiado pela FCT (Projecto PRAXIS/2/2.1/CSH/819/95). 


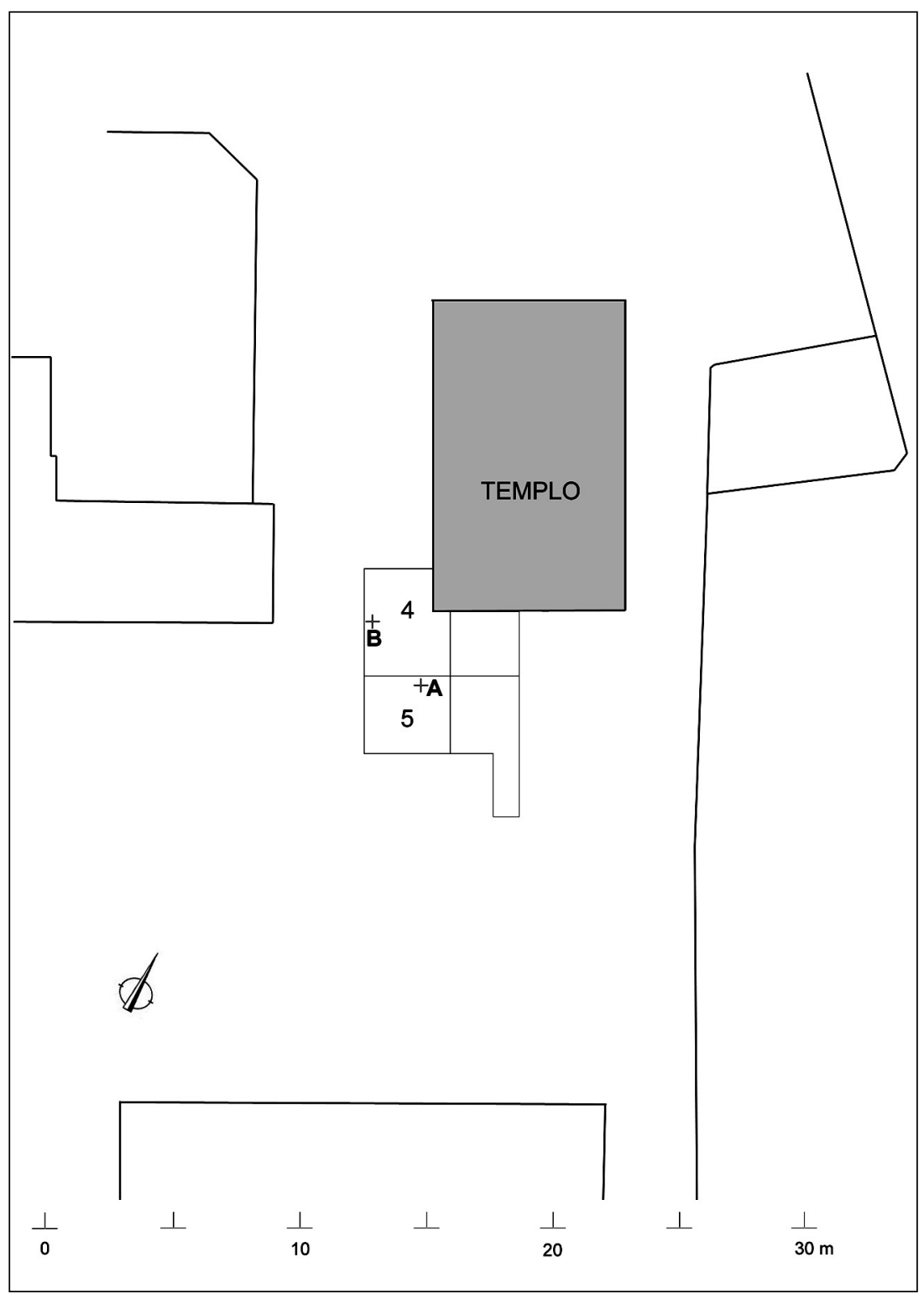

FIG. 1 - Esboço da planta da zona do Templo Romano de Évora com a situação das sondagens $4 / 5$ e dos lugares onde foram achados os fragmentos de mármore A e B. 


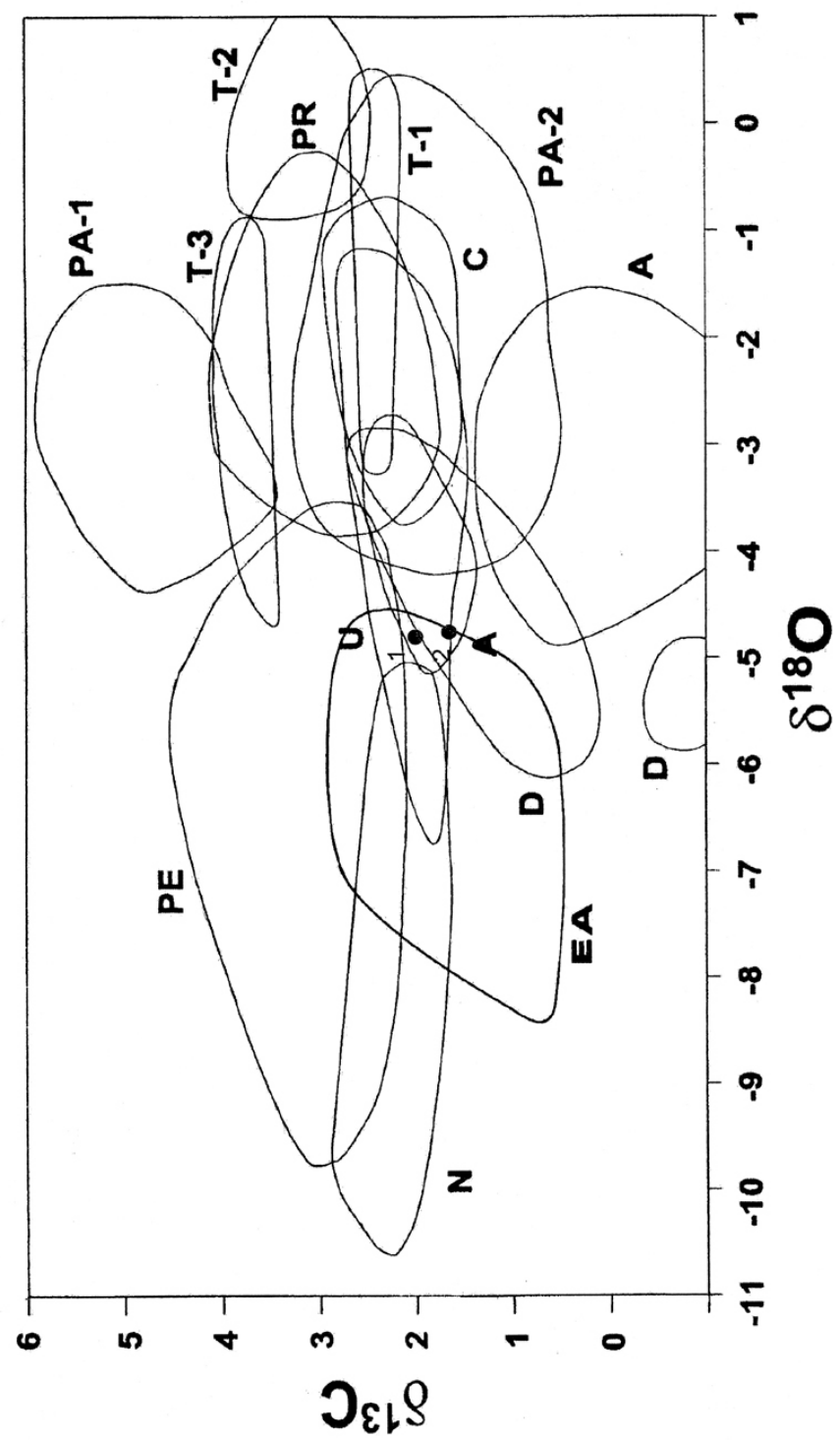

FIG. 2 - Projecções dos pontos representativos das amostras 1 e 2, extraídas dos fragmentos de mármore A e B dos capitéis do Templo Romano de Évora. Campos característicos das composições isotópicas dos mármores do Anticlinal de Estremoz e de diversos mármores brancos das pedreiras mais importantes exploradas na Antiguidade Clássica: EA - Anticlinal de Estremoz; A - Afrodisíade; C - Carrara; D - Dokimeion; N - Naxos; PA-1 - Paros Stefani; PA-2 - Paros Chorodoki; PE - Monte Pentélico; PR Proconeso (Mármara); T-1, T-2, T-3 - Tasos; U - Usak. 